\title{
Anaesthetic Management during Intracardiac Surgery for Tetralogy of Fallot Associated with Trisomy 18
}

\author{
Mayo Miyata ${ }^{1}$, Yusuke Naito ${ }^{1 *}$, Yuka Akasaki ${ }^{1}$, Mitsuru Ida ${ }^{1}$, Ryohei Fukuba ${ }^{2}$, Shinya \\ Yokoyama $^{2}$, Masahiko Kawaguchi ${ }^{1}$ \\ ${ }^{1}$ Department of Anesthesiology, Nara Medical University, Japan \\ ${ }^{2}$ Department of Cardiac Surgery, Nara Medical University, Japan
}

*Corresponding Author: Yusuke Naito, Department of Anesthesiology, Nara Medical University, Japan

\begin{abstract}
There is much controversy regarding the performance of cardiac surgery on patients with trisomy 18 because of the high risk of mortality during surgery and the postoperative period. Therefore, reports on cardiovascular surgery on patients with trisomy 18 are rare. In addition, these few case reports focus on surgical management and reports discussing anaesthetic management, especially for complex procedures, are still lacking. We report a 2-month-old male infant with trisomy 18 and tetralogy of Fallot who underwent primary intracardiac repair. Our report indicate that intracardiac repair can be successfully performed on patients with tetralogy of Fallot associated with trisomy 18. However, pulmonary vascular resistance fluctuation may not be avoided with deep anesthesia alone.
\end{abstract}

\section{INTRODUCTION}

Trisomy 18 (Edward's Syndrome) is the second most common autosomal trisomy, occurring inone in every 3,500-8,500 births. The median postnatal survival of children with trisomy 18 is 3 to 4.5 days [1]. Congenital heart disease is observed in $90 \%$ of infants born with trisomy 18 and the cardiac malformation varies from a simple left to right shunt, such as arterial septum defect or ventricular septum defect, to more complex malformations, such as hypoplastic left heart syndrome.There is much controversy regarding the performance of cardiac surgery on patients with trisomy 18 because of the high risk of mortality during surgery and the postoperative period [2].

Therefore, reports on cardiovascular surgery on patients with trisomy 18 are rare. In addition, these few case reports focus on surgical management and reports discussing anaesthetic management,especially for complex procedures, are still lacking.

This paper describes the anaesthetic management of a case ofsingle-stageintracardiac repair (ICR) for a child with trisomy 18 and tetralogy of Fallot (TOF) associated with trisomy 18.

\section{CASe Report}

The patient was a 2-month-old boydiagnosed with TOF prenatally. He was delivered by emergent caesarean section at another hospital because ofnon-reassuring foetal status. Apgar scoreswere 4 and 5 at $1 \mathrm{~min}$ and $5 \mathrm{~min}$, respectively.His trachea was immediately intubated since significant intercostal retractions and weak cry were observed, and he was transferred to our hospital.

On day $11, \mathrm{SpO}_{2}$ decreased to $70 \%$ because of patent ductus arteriosus narrowing and alprostadil $(0.02 \mathrm{mcg} / \mathrm{kg} / \mathrm{min})$ was initiated. On day 20, tracheal extubation was attempted but was unsuccessful because of frequenthypoxic spellsand an abnormal breathing pattern due to laryngomalacia. Extubation failed againon day 53.Contrast computed tomography examinationshowed low aortic arch, sooriginal Blalock Taussig (BT) shunt using a native artery wasconsidered anatomically difficult. Furthermore, a modified BT shunt requires anticoagulation, and tracheostomy would be difficult.

Afterconsultation, his family requested primary ICR, despite the potential risks. Perioperative echocardiogram findings were: left ventricular end diastolic volume $144 \%$ of normal, right ventricular end diastolic volume $455 \%$ of normal,Qp/Qs 1.92, Rp 4.65, PA index of 215. Preoperative laboratory values were with in normal limits.

No premedication was given prior to anaesthesia induction. He was transferred to the operating 
room with his trachea intubated and an intravenous line. Anaesthesia was introducedby administration of $0.3 \mathrm{mg}$ midazolam, $20 \mathrm{mcg}$ fentanyl, and $3.75 \mathrm{mg}$ rocuronium bromide. After anaesthesia induction, we exchanged the 3.5$\mathrm{mm}$ diameter uncuffed tracheal tube for a 3.0$\mathrm{mm}$ Microcuff ${ }^{\circledR}$ tube (Halyard Healthcare, Yokohama, Japan) with direct laryngoscopy.

Arterial access and the central venous line were obtained via the right radial artery and right internal jugular vein. Anaesthesia was maintained using controlled ventilation with sevoflurane $1.5-2.0 \%$ in $40: 60 \%$ oxygen in air.

Central venous artery saturation and central venous pressurewere monitoredusinga PediaSat@oximetry catheter (Edwards Lifesciences, Irvine, CA). Until separation from cardiopulmonary bypass (CPB), the operation was uneventful.

The total dose of midazolam and fentanyl was $8 \mathrm{mg}$ and300mcg,respectively. ICR was performed with ventricular septum defect closure andright ventricular outflow tract resection. Mechanical ventilation was reinitiated with $\mathrm{FIO}_{2} 100 \%$ with $20 \mathrm{ppm} / \mathrm{L}$ nitric oxide and a setting of $25 \mathrm{~mL} / \mathrm{breath}$ to maintaina $30-35$ $\mathrm{mmHg} \mathrm{PaCO}_{2}$. Despite adequate inotropic support (dopamine: $5 \mathrm{mcg} / \mathrm{kg} / \mathrm{min}$, dobutamine: $5 \mathrm{mcg} / \mathrm{kg} / \mathrm{min}$, epinephrine $0.1 \mathrm{mcg} / \mathrm{kg} / \mathrm{min}$ ) and

\section{Preoperative Events}

day 0: intubated, transferred to our hospital

day 11: initiation of alprostadil

day 20: unsuccessful extubation

day 53: unsuccessful extubation

\section{Discussion}

To the best of our knowledge, this is the first case report documenting anaesthetic management of ICR for TOF associated with trisomy 18. Although there is a strong view that ICR should be followed by a BT shunt, especially for low birthweight infantsbecause of the high risk of organ failure, the benefits of early ICR include release from early pressure overload, reduction of arrhythmia events, shunt thrombosis, and congestive heart failure. Tamesberger et al. demonstrated high survival ratesusing primary ICR for asymptomatic TOF in infants aged 2 to 3 months and those with symptomatic TOF 3]. ICR was chosen in this case because we could not perform a BT shunt, and congestive heart failure remains the major cause of death in infants with trisomy 18 ,so avoiding BTS might benefit some cases.

Previously, cardiac surgery for trisomy 18 was thought to be contraindicated because cardiac volume load, cardiac contraction was reduced.Central venous arterysaturation values gradually decreased, eventually to $30 \%$ after separation from CPB. Full discussion was made between the anaesthesiologist and cardiac surgeonsand decided to close the chest.After sternal closure, sudden increase in peak inspiratory pressure with decrease in tidal volume was observed. Furthermore, hemodynamic instability was observed, indicating $\mathrm{PH}$ crisis.

Administration of fentanyl, calcium chloride, and sodium bicarbonate, supplemented with bolus administration ofadrenaline was performed, but sufficient recovery could not be achieved.Therefore, we decided to reopen the sternum.

Circulatory and respiratory instability persisted. When we moved the patient forpostoperative chest X-ray, he had PH crisis again and required temporal cardiopulmonary resuscitation.

On postoperative day3,sternal closure was performed and his trachea was extubated on day 4 without significant events.

A tracheostomy was performed on day 34 , and hewasdischarged.

Table1: Summary of Pre and Postoperative Events

Postoperative Events

day 3: sternal closure

day 4: extubation

day 34: discharged from hospital

surgery failed to demonstrate an improvement in the number of days of survival [2].This situation is similar to Down's Syndrome, whichwas historicallyconsidered a condition for which non-intervention in the new-bornis indicated [4]. However, rapid improvementinpostoperative survival rateshas rendered surgery more common for this condition [ 4]. For trisomy 18, recently reported 28-day and 1-year survival rates were $36 \%$ and $13 \%$, respectively. In addition, survival rates differ greatly among the regions in this study, indicating that the survival rate varies greatly depending on the management. However, many health care workers still consider that trisomy 18 is lethal and that survivors cannot live a meaningful life [5]. In the future, with anticipated break throughsin medical treatment, interventions for trisomy 18 will rapidly improve, along with improvements inanaesthesia management. However, reportson anaesthesia management for 
patients with trisomy 18 are still lacking.

There are several anaesthetic considerations associated with trisomy 18 . Previously reported concerns are difficult airway management, symptoms like malignant hyperthermia, and the fluctuation of pulmonary resistance.Malignant hyperthermia (high body temperature and muscle rigidity) wasreported in one case using succinylcholine in Japan [6]. However, succinylcholinehas been reported as safe in subsequent reports [7]. It is still unclear whether trisomy 18 is the sole factor contributing to malignant hyperthermia; however, it is still advisable to avoid succinylcholine where possible. In our case, rocuronium bromide was used as a muscle relaxant.Difficultiesin securing the airwayhave created controversy in previous reportsand the difficulty seems to vary from case to case [7]. Craniofacial abnormalities (micrognathia, dolichocephaly and short palpebral fissures)are often associated with trisomy 18 and can make intubation difficult.It isalso noted that upper airway obstruction is likely to be more common than previously realised and a full investigation is needed prior to anaesthetic induction [8]. In our case, initial intubation in the other hospital was described as difficult; however, subsequentintubations seemed to beeasier using direct laryngoscopy in the neonatal department,according to medical records. Moreover, when we exchanged the tracheal tube in the operating room, the epiglottis and vocal cords were seen clearly, so the Cormack grade was classified as grade 1 . There were no recorded difficulties in mask ventilation in our case.

Finally, PH was a major problem in our case. The association between chromosome aberration and $\mathrm{PH}$ is well studied in Down's Syndrome cases. In Down's syndrome, vasodilative products such as prostacyclin and nitric oxide are decreased, while the level of vasoconstrictive products in the blood, such as thromboxane and endothelin, is increased [9].These characteristics are related to media thickening and intimal hyperplasia in the pulmonary artery, which is also commonly seen in trisomy 18 [10]. An increase in PVR is triggered by dysfunction of the inner layer of the pulmonary artery by inflammatory substances from CPB. Hypoxemia, hypercapnia, and acidosis are also factors that increase PVR by activating the sympathetic nerve system. Therefore, deep anaesthesia is recommended in cases for which $\mathrm{PH}$ crisis is predicted. In our case, 300mcgof fentanyl, $8 \mathrm{mg}$ of midazolam, and an effective dose of rocuronium bromidewere administered at the time of separationfrom $\mathrm{CPB}$, and this depth of anaesthesia was effective. However, stimulation associated with sternal closurecaused $\mathrm{PH}$ crisis, suggesting that the PVR fluctuation may not be avoided with deep anaesthesia alone. Although blood pressure and $\mathrm{SpO}_{2}$ were within normal limits, regional oxygen saturation index valuesshowed adeclining trend, and thus his hemodynamic status was critical. It might be reasonable to keep the sternum open in such situations.

In conclusion, we have described our experience of a case of TOF repair associated with trisomy 18. Cardiac surgery for infants with trisomy 18 remains controversial. Further case reports are needed to increase evidence supporting the perioperative management of children with trisomy 18. Furthermore, as PVR fluctuation is similar to that seen in Down'sSyndrome, extreme caution is necessary to avoid PH crisis.

\section{AUTHORS' CONTRIBUTIONS}

All authors were involved in the treatment of the patient. MM and YA performed anesthetic management. YN collected the patient's data and drafted the manuscript. MI and MKrevised and edited the manuscript. RF and SY performed surgery. All authors contributed and approved the final version of this manuscript.

\section{REFERENCES}

[1] Meyer RE, Liu G, Gilboa SM, Ethen MK, Aylsworth AS, Powell CM et al. Survival of children with trisomy 13 and trisomy 18: A multi-state population-based study. American journal of medical genetics Part A. 2016; 170a:825-37.

[2] Graham EM. Infants with Trisomy 18 and Complex Congenital Heart Defects Should Not Undergo Open Heart Surgery. The Journal of law, medicine \& ethics : a journal of the American Society of Law, Medicine \& Ethics. 2016; 44:286-91.

[3] Tamesberger MI, Lechner E, Mair R, Hofer A, Sames-Dolzer E, Tulzer G. Early primary repair of tetralogy of fallot in neonates and infants less than four months of age. The Annals of thoracic surgery. 2008; 86:1928-35.

[4] McCaffrey MJ. Trisomy 13 and 18: Selecting the road previously not taken. American journal of medical genetics Part C, Seminars in medical genetics. 2016; 172:251-6.

[5] Wilkinson D, de Crespigny L, Xafis V. Ethical language and decision-making for prenatally diagnosed lethal malformations. Seminars in fetal \& neonatal medicine. 2014; 19:306-11. 
[6] Matsuda H, Kaseno S, Gotoh Y, Furukawa K, Imanaka K. [Muscle rigidity caused by succinylcholine in Edwards' syndrome]. Masui The Japanese journal of anesthesiology. 1983; 32:125-8.

[7] Mifsud S, Bezzina M, Paris S. Anesthetic management of a patient with Edwards syndrome. Clinical case reports. 2016; 4:740-2.

[8] Cereda A, Carey JC. The trisomy 18 syndrome. Orphanet journal of rare diseases. 2012; 7:81.
[9] Saji T. Clinical characteristics of pulmonary arterial hypertension associated with Down syndrome. Pediatrics international: official journal of the Japan Pediatric Society. 2014; 56:297-303.

[10] Van Praagh S, Truman T, Firpo A, BanoRodrigo A, Fried R, McManus B et al. Cardiac malformations in trisomy-18: a study of 41 postmortem cases. Journal of the American College of Cardiology. 1989; 13:1586-97.

Citation: Mayo Miyata, Yusuke Naito, Yuka Akasaki et.al. Anaesthetic Management during Intracardiac Surgery for Tetralogy of Fallot Associated with Trisomy 18. ARC Journal of Anesthesiology. 2020; 5(1): 0407. DOI: dx.doi.org/10.20431/2455-9792.0501002.

Copyright: (C) 2020 Authors. This is an open-access article distributed under the terms of the Creative Commons Attribution License, which permits unrestricted use, distribution, and reproduction in any medium, provided the original author and source are credited. 